Southern Illinois University Carbondale

OpenSIUC

Discussion Papers

Department of Economics

$2-2011$

\title{
Piecemeal Reform of Domestic Indirect Taxes toward Uniformity in the Presence of Pollution: with and without a Revenue Constraint
}

\author{
Michael S. Michael \\ University of Cyprus \\ Sajal Lahiri \\ Southern Illinois University Carbondale \\ Panos Hatzipanayotou \\ Athens University of Economics and Business
}

Follow this and additional works at: http://opensiuc.lib.siu.edu/econ_dp

Discussion Paper 2011-01

J.E.L Classification: H21, H23

\section{Recommended Citation}

Michael, Michael S.; Lahiri, Sajal; and Hatzipanayotou, Panos, "Piecemeal Reform of Domestic Indirect Taxes toward Uniformity in the Presence of Pollution: with and without a Revenue Constraint" (2011). Discussion Papers. Paper 83.

http://opensiuc.lib.siu.edu/econ_dp/83

This Article is brought to you for free and open access by the Department of Economics at OpenSIUC. It has been accepted for inclusion in Discussion Papers by an authorized administrator of OpenSIUC. For more information, please contact opensiuc@lib.siu.edu. 


\title{
Piecemeal Reform of Domestic Indirect Taxes toward Uniformity in the Presence of Pollution: with and without a Revenue Constraint
}

\author{
Michael S. Michael*, Sajal Lahiri`and Panos Hatzipanayotou^
}

February 2, 2011

\begin{abstract}
The literature on indirect tax reforms in pollution-ridden economies is quite limited. This paper, using a general model of a perfectly-competitive small open economy with both production and consumption generated pollution, considers the welfare implications of tax reforms that take the structure of consumption and production taxes toward uniformity. Specifically, both in the presence and absence of a binding government revenue constraint, we derive sufficient conditions for welfare improvement in the case where we implement $(i)$ reforms in either production or consumption taxes, and (ii) reforms in both consumption and production taxes.
\end{abstract}

Keywords: Indirect tax reforms, Production and consumption generated pollution, Welfare, Government tax revenues.

J.E.L Classification: H21: Efficiency, Optimal Taxation $\mathrm{H} 23$ : Production taxes and subsidies

* Department of Economics, University of Cyprus; P.O.Box 20537, CY 1678, Nicosia, Cyprus, and Cesifo (Center for Economic Studies and the Ifo Institute of Economic Research), Email: m.s.michael@ucy.ac.cy

-Department of Economics, Southern Illinois University Carbondale, Carbondale, IL. 62901-4515, U.S.A., E-mail: lahiri@ siu.edu

` Department of International and European Economic Studies, Athens University of Economics and Business; 76, Patission str., Athens 104 34, Greece, and CESifo, Email: hatzip@aueb.gr 


\section{Introduction}

During the past couple of decades there has been a general consensus regarding the reforms of national tax systems. International institutions, e.g., the WTO, the IMF and the World Bank, encourage governments to reform their indirect and direct tax structure in a way of reducing economic distortions, improving welfare and possibly ensuring higher levels of government tax revenues. ${ }^{1}$ Amongst the various types of recommended reforms, two seems to stand out. First is the need of countries to reduce their reliance on discriminatory trade taxes and switch to domestic taxes such as income taxes and consumption taxes. ${ }^{2}$ The second class of recommended reforms involves just domestic taxes such as the movement of taxes towards uniformity.

Motivated by such developments in the policy arena, a voluminous academic literature on tax reforms has been developed examining a wide range of reforms in direct and indirect taxes. This paper is not about the first type of reforms mentioned above ${ }^{3}$ but about the second type. Within the class of reforms of domestic taxes, there are many subclasses. A strand of this literature examines the relationship between direct and indirect taxes (see, for example, Atkinson and Stiglitz, 1976); another examines the movement from destination to origin principle of commodity taxation (see, for example, Lockwood et al., 1994 and Keen and Lahiri, 1998); a third examines the implications of moving domestic taxes on different goods towards a uniform rate (se, for example, Hatta, 1977, 1986). ${ }^{4}$

Specifically of interest to our study is the literature that considers the implications of a move towards uniformity of domestic taxes across goods. The origins of this

\footnotetext{
1 This latter concern becomes even more important for revenue-strained developing economies. Achieving these two goals, countries are able to attain a so-called "double-dividend". That is, a tax system which improves welfare and does not reduce tax revenues.

${ }^{2}$ According to the World Bank (2002), during the 1990s in low- and medium-income countries, the share of domestic indirect taxes (i.e., taxes on goods and services) in total current government revenue rose from 26 percent in 1990 to 36 percent in 1999. During the same period the share of trade taxes fell from 17 percent to 9 percent.

3 The literature here is quite substantial and growing. See. For example, Diewert et al., 1989; Michael et al., 1993; Hatzipanayotou et al., 1994, Abe, 1995; Neary, 1998; Keen and Ligthart, 2002; Lahiri and Nasim, 2005; Emran, 2005; Emran and Stiglitz, 2005; Boadway and Sato, 2009. All the above studies examine the welfare and revenue implications of domestic and/or trade tax reforms in the context of a static general equilibrium model of a small open economy. Among others, Majumdar (2004), Keen and Ligthart (2005) and Naito and Abe (2008) examine the welfare implications of indirect tax reforms under a revenue neutrality constraint in the context of imperfect competition. Naito (2005 and 2006) examine dynamic policy aspects, e.g., the growth rate of output, of such tax reforms.

4 There is also a large literature on the uniformity of domestic taxes across tax jurisdictions ---the issue of tax harmonization --- starting with the seminal work by Keen (1987), and on the uniformity of domestic environmental taxes across heterogeneous firms within an industry (see, for example, Fullerton et al., 2008).
} 
literature dates back to Atkinson and Stiglitz (1976) who show that, when income tax is set optimally, differential commodity taxation is inefficient. ${ }^{5}$ Hatta (1977) in the context of a closed economy and without considering a binding tax revenue constraint, examines the welfare implications of moving consumption taxes towards uniformity, while Hatta (1986), re-examines the implications of the above tax reforms under a revenue constraint. The broad argument here is that non-uniformity in commodity taxation distorts consumption choices and therefore is inefficient. A move toward this type of uniformity is also a live issue in the policy-making sphere (see, for example, The European Union, 2010).

During the past few decades most countries including many developing ones -e.g., the so-called BRICS countries Brazil, Russia, India, China and South Africa -have enjoyed a speedy and strong growth. For theorists and policy makers, however, this process of economic growth has raised a number of serious concerns. Among those foremost is the threat to the quality of the environment due to the intensification of economic activity. To deal with these concerns, a new strand of the tax reform literature has been developed, which examines the implications of changes in the structure of indirect taxes in the context of pollution ridden open economies. Among others, Copeland (1994), Beghin et al. (1997), Turunen-Red and Woodland (2004), Kayalica and Kayalica (2005) consider the welfare and environmental implications of reforms in trade and domestic taxes in economies where pollution is a by product of the production and/or consumption. This literature however does not account for a binding government revenues constraint, ${ }^{6}$ Beghin and Dessus (1999) being a notable exception. ${ }^{7}$ To the best of our knowledge there are no studies on the reforms of domestic indirect taxes --- particularly on the movement toward uniformity of

\footnotetext{
${ }^{5}$ Kaplow (2006) shows that the Atkinson-Stiglitz(1976) result can hold even when income tax is not optimal.

${ }^{6}$ A different literature examines the so-called double-dividend hypothesis of green tax reforms, whereby pollution taxes simultaneously corrects for the pollution externality and raises government revenues, e.g., Bovenberg and van der Ploeg (1994), Bovenberg and De Mooij (1994) Goulder (1995) and Bovenberg (1999) provide various meanings of the term "double-dividend" and extensive surveys of this literature. Finally, a different framework of pollution tax reforms is developed by Hatzipanayotou et al. (2005) who in a two-country model with cross-border pollution and public pollution abatement, examine the welfare implications of selected multilateral environmental policy reforms.

${ }^{7}$ Beghin and Dessus (1999), show that piecemeal tax reforms that reduce domestic relative tariffs towards uniformity and increasing emissions taxes proportionally, improve welfare, reduces pollution, without deteriorating government tax revenues.
} 
domestic indirect taxes across goods --- in the presence of pollution and government revenue constraint.

This paper considers reforms of indirect taxes along the lines of the literature on tax reforms in pollution ridden economies. The present study, however, extends the above literature in two ways. First, although our analytical framework is one of an open economy, we depart from the standard paradigm of reforms in domestic vs. trade taxes by considering reforms of only domestic taxes and consider reforms that move production and consumption taxes toward uniformity across goods. Such a framework could be more relevant since trade barriers have been rapidly going down. Second, and in contrast to the bulk of the relevant literature, the proposed tax reforms also account for a binding government revenue constraint.

To this end, we consider a small open economy where pollution is generated either by production or by consumption, and where the government raises revenue by imposing production and/or consumption emission taxes. We consider the cases where government revenue constraint is binding as well as when it is not binding. Under these different scenarios, we derive sufficient conditions for welfare improvement in the specific types of reforms mentioned above; we consider reforms of consumption taxes and production taxes on their own and also the case when both types of taxes are reformed at the same time. ${ }^{8}$

\section{The General Model}

We consider a small open, perfectly competitive economy which produces and consumes $\mathrm{K}$ internationally traded goods. There are $K$ types of pollutants associated with the production or consumption of these goods. The country is endowed with the inelastic supply of $M$ primary factors, denoted by the vector $\bar{v}$.

Pollution is modeled as a by-product of both production and consumption. The production or consumption of each commodity generates a different type of pollutant which affects negatively the households' utility. Consumption and production taxes are levied by the government to discourage respectively pollution-generating consumption by the country's households and pollution-generating production by the producers. All tax revenues are lump-sum distributed to domestic households.

\footnotetext{
${ }^{8}$ We do not consider the distributional implications of the reforms. See, for example, Saez (2002) for an analysis of the Atkinson-Stiglitz (1976) results in the presence of heterogeneous consumers.
} 
The country is a price taker in world commodity markets. ${ }^{9}$ The international prices of all goods are assumed to equal unity, and are denoted by the price vector $p^{*^{\prime}}=(11 \ldots 1), \mathrm{a}(1 \times K)$ vector of unit-scalars. ${ }^{10}$

The economy's production side is represented by the revenue function $R(q, \bar{v})$ which captures the economy's maximum revenue from production of the internationally traded goods with vector of factors $[\bar{v}]$ and vector of producer prices $q$, where $q_{j}=1^{-} t_{j}$ is the domestic producer price of the $j^{t h}$ commodity and $t_{j}$ is the specific production tax levied on it. For the rest of the analysis, since the vector of factor endowments $\bar{v}$ remains unchanged, the revenue function is denoted by $R(q)$. The $R(q)$ function is assumed convex and homogeneous of degree one in producer prices. By the envelop theorem $R_{q_{j}}\left(=\partial_{R} / \partial_{q_{j}}\right)$ is the supply function of the $j^{\text {th }}$ good.

Turning to the demand side of this economy, it comprises of identical households who consume the $K$ commodities, and whose utility is adversely affected by production and consumption generated pollution. A representative household's preferences are captured by the expenditure function $E(p, z, r, u)$ denoting the minimum expenditure on private goods achieving a certain level of utility $(u)$, at consumer price vector $p$ and vectors of production pollutants $z$ and consumption pollutants $r$. The domestic consumer price for the $j^{\text {th }}$ commodity is $p_{j}=1^{+} \tau_{j}$, where $\tau_{j}$ denotes the specific consumption tax levied on it. The $E(p, z, r, u)$ function is increasing in $u$, in levels of pollution $z$ and $r$, and non-decreasing and concave in p. ${ }^{11}$ The derivative $E_{p_{j}}=\partial_{E} / \partial_{p_{j}}$ is the compensated demand for the $\mathrm{j}^{\text {th }}$ good and $E_{p p}$ is a $(K \times K)$ negative semi-definite matrix. The derivative $E_{u}$ captures the inverse of the marginal utility of income. The derivative $E_{z_{i}}$ and $E_{r_{i}}$, respectively, denote the marginal damage caused by the pollutant $z_{j}$ or $r_{i}$, and thus they represents the household's marginal willingness to pay for its reduction (e.g., see Copeland, 1994).

\footnotetext{
${ }^{9}$ We follow a standard practice of the literature of indirect tax reforms, which, by and large, for analytical convenience confines the analysis of such tax reforms in the context of small open economies, i.e., terms of trade considerations, are unaccounted for.

${ }^{10}$ A prime (') denotes a transposed vector or matrix.

${ }^{11}$ The $E$ (.) function is increasing in $z$ or in $r$ since an increase in any type of pollutant is assumed to harm the households' utility. Therefore, to attain a given level of utility, $u$, private spending on consumption must rise.
} 
Let, $z_{j}=\alpha_{j} R_{q_{j}}(q)$ and $r_{j}=\beta_{j} E_{p_{j}}(p, z, r, u)$, respectively denote the levels of pollution associated with the production and consumption of the $j^{\text {th }}$ good. The scalars $\alpha_{j}>0$ and $\beta_{j}>0$ denote, respectively, the units of production and consumption pollution per unit of the $j^{\text {th }}$ commodity.

The government's tax revenue, $(T)$, which is distributed to households in a lump-sum fashion, equals the sum of consumption and production tax revenues, i.e.,

$$
T=\tau^{\prime} E_{p}(p, z, r, u)+t^{\prime} R_{q}(q)=\sum_{j=1}^{K} \tau_{j} E_{p_{j}}(p, z, r, u)+\sum_{j=1}^{K} t_{j} R_{q_{j}}(q),
$$

where $E_{p}$ and $R_{q}$, respectively, are the vectors of compensated demand and supply of goods. The country's income-expenditure identity requires that private spending on goods must equal income from production plus income from government taxes. Thus, the country's budget constraint is given as follows:

$$
E(p, z, r, u)=R(q)+\tau^{\prime} E_{p}(p, z, r, u)+t^{\prime} R_{q}(q) .
$$

Equations (1) and (2) are the main equations of the model. They are used to examine the welfare implications of reforms in production and consumption taxes under two scenarios, with and without government revenue constraint.

We conclude this section by deriving the effects of changes in production and consumption taxes on the levels of welfare and government revenues. Differentiating equation (2), we obtain:

$$
E_{u} d u=\tau-\beta E_{r}{ }^{\prime} d E_{p}+t-\alpha E_{z}{ }^{\prime} d R_{q},
$$

where, a "hat" over a variable denotes a diagonal matrix. Thus, $\alpha$ and $\beta$, respectively are $(K \times K)$ diagonal matrices whose elements indicate the amount of production and consumption pollution per unit of the $j^{\text {th }}$ output. Also, ${ }^{12}$

\footnotetext{
12 Subscripts on the functions, i.e., $E_{p_{j} p_{i}}, E_{p_{j} z_{j}}, E_{p_{j} r_{j}}, E_{p_{j} u}$ and $R_{q_{j} q_{n}}$ denote partial derivatives. For example, $E_{p_{j} p_{i}}=\partial_{E_{p_{j}}} / \partial p_{i}, R_{q_{j} q_{n}}=\partial_{R_{q_{j}}} / \partial_{q_{n}}$. It is to be noted that $E_{p_{j} p_{i}}>0(<0)$ if the $j^{\text {th }}$ and $i^{\text {th }}$ goods are substitutes (complements) in consumption, $E_{p, u}, \forall_{j} \in K$, is positive assuming that all good are normal in consumption, and $R_{q_{j} q_{n}}<0(>0)$ if the $j^{\text {th }}$ and $n^{\text {th }}$ goods are substitutes (complements) in production.
} 


$$
\begin{aligned}
& d E_{p}=E_{p p} d \tau+E_{p r} d r+E_{p z} d z+E_{p u} d u, \text { and } \\
& d R_{q}=-R_{q q} d t
\end{aligned}
$$

For the rest of the analysis, we assume, for simplicity, that goods and clean environment are independent in consumption, i.e., $E_{p r}=E_{p z}=0 .^{13}$

Equation (3) can be rewritten so as to capture the welfare effect of changes in a single consumption tax, say that on the $i^{\text {th }}$ good, and of changes in a single production tax, say on the $n^{\text {th }}$ good. That is: ${ }^{14}$

$$
\Omega d u=\sum_{j=1}^{K}\left(\tau_{j}-\beta_{j} E_{r_{j}}\right) E_{p_{j} p_{i}} d \tau_{i}-\sum_{j=1}^{K}\left(t_{j}-\alpha_{j} E_{z_{j}}\right) R_{q_{j} q_{n}} d t_{n},
$$

where $\Omega=E_{u}-\sum_{j=1}^{K}\left(\tau_{j}-\beta_{j} E_{r_{j}}\right) E_{p_{j} u}$, it is assumed positive and this is the standard practice in the tax reform literature. It represents the general equilibrium inverse of the marginal utility of income; inclusive of feedback via consumption taxes and consumption generated pollution. Equation (6) can be further elaborated on by using the properties of the expenditure and revenue functions that compensated demand and supply functions are homogeneous of degree zero in prices. Specifically, $\sum_{j=1}^{K} p_{j} E_{p_{j} p_{i}}=0$ and $\sum_{j=1}^{K} q_{j} R_{q_{j} q_{n}}=0$, respectively, yield $E_{p_{i} p_{i}}=-\sum_{j \neq i}^{K} p_{j} / p_{i} E_{p_{j} p_{i}}$ and $R_{q_{n} q_{n}}=-\sum_{j \neq n}^{K} q_{j} / q_{n} R_{q_{j} q_{n}}$. Note that $p_{k}=1+\tau_{k}, q_{k}=1-t_{k}, \quad k=j, i, n$, and by the

\footnotetext{
${ }^{13}$ In the analysis to follow we assume $E_{p r}=E_{p z}=0$ while $E_{p u} \geq 0$. Suppose that the direct utility function has the following form $u=y^{a}\left(x^{-} z\right)^{1-a}$ where $(x, y)$ is the vector of consumptions of the two goods and $z$ is the level of pollution. It can be shown that the expenditure function in this case is $E(p, u, z)=a^{-a}(1-a)^{1-a} p^{a} \bar{u}+z$, where $p\left(=p_{y} / p_{x}\right)$. Clearly, this expenditure function satisfies $E_{p z}=0$ and $E_{p u}>0$. The assumption that the demand for private goods is independent of the environmental quality is often made in the literature (i.e., Bovenberg 1999, Beghin and Dessus 1999). Wilson (1991) provides an example of a direct utility function and Copeland and Taylor (2004) an example of an indirect utility function which gives uncompensated demand functions for goods independent of public good and pollution, respectively.

${ }^{14}$ In this case, equation (3) is $d u=\sum_{j=1}^{K}\left(\tau_{j}-\beta_{j} E_{r_{j}}\right) d E_{p_{j}}+\sum_{j=1}^{K} t_{j}-\alpha_{j} E_{z_{j}} d R_{q_{j}}$. Simple algebra, using the relevant equations (4) and (5), and assuming that $E_{p_{j} r_{j}}=E_{p_{j} z_{j}}=0$, result in equation (6).
} 
reciprocity conditions $E_{p_{k} p_{j}}=E_{p_{j} p_{k}}$ and $R_{q_{k} q_{j}}=R_{q_{j} q_{k}}$. Using the above properties and after some manipulations, we obtain:

$$
\Omega d u=\sum_{j \neq i}^{K}\left(\sigma_{j}-\sigma_{i}\right) p_{j} E_{p_{j} p_{i}} d \tau_{i}-\sum_{j \neq n}^{K}\left(s_{j}-s_{n}\right) q_{j} R_{q_{j} q_{n}} d t_{n} .
$$

We call the ratio $\sigma_{k}=\left(\tau_{k}-\beta_{k} E_{r_{k}}\right) / p_{k}$, the rate of excess taxation of consumption-pollution, which can be positive or negative depending on whether the consumption tax exceeds or falls below the marginal willingness to pay for reducing pollution due to consumption of a unit of the $k^{\text {th }}$ good. ${ }^{15}$ Similarly, the ratio $s_{k}=\left(t_{k}-\alpha_{k} E_{z_{k}}\right) / q_{k}$ is called the rate of excess taxation of production-pollution, which can also be positive or negative depending on whether the production tax exceeds or falls below the marginal willingness to pay for reducing pollution due to production of a unit of the $k^{\text {th }}$ good.

When government revenue constraint is binding $(d T=0)$, differentiating equation (1), using equations (4), (5), and the homogeneity properties of the expenditure and revenue functions, we obtain:

$\delta_{d u}+\left\lceil p_{i} E_{p_{i}}+\sum_{j \neq i}^{K} \tau_{j}-\tau_{i} E_{p_{j} p_{i}}\right\rfloor \frac{d^{\tau} \tau_{i}}{1+\tau_{i}}+\left\lceil q_{n} R_{q_{n}}+\sum_{j \neq n}^{K} t_{n}-t_{j} R_{q_{j} q_{n}}\right\rfloor \frac{d t_{n}}{1-t_{n}}=0$,

where, $\delta=\sum_{j=1}^{K} \tau_{j} E_{p_{j} u}$ and it is positive assuming that goods are normal in consumption.

Equations (3) and (7) are relevant for examining the welfare implications of the indirect tax reforms assuming a non-binding government revenue constraint. The system of equations (3), (7) and (8) are used to examine the welfare implications of indirect tax reforms under a binding government revenue constraint.

\footnotetext{
15 Note that $p_{k}^{-1} E_{r_{k}} \beta_{k}=p_{k}^{-1}\left(\partial E / \partial r_{k}\right)\left(\partial r_{k} / \partial_{p_{k}}\right)$ is the amount by which consumers need to be compensated in order to keep utility constant due pollution generated by a Euro's worth increase in consumption of the $k^{\text {th }}$ good. $\tau_{k} / p_{k}$ is the ad-valorem equivalent of the specific consumption tax $\tau_{k}$ on the $k^{\text {th }}$ good.
} 


\section{Reforms without a binding government revenue constraint}

In this section, we assume away the existence of a government revenue constraint and examine the welfare implications of reforms in consumption taxes and in production taxes. We consider these one at a time, but in the presence of both types of pollution and both types of taxes.

\subsection{Reforms in consumption taxes}

In this subsection we derive the conditions under which welfare improves by increasing or decreasing the consumption tax on a certain good. In this exercise we do not consider changes in production taxes whose non-zero levels are held constant. With this in mind, whether there exist production generated pollution and/or production taxes does not affect the results to follow. Since production taxes do not change, equation (7) reduces to:

$$
\Omega d u=\sum_{j=1}^{K} \tau_{j}-\beta_{j} E_{r_{j}} E_{p_{j} p_{i}} d \tau=\sum_{j \neq i}^{K}\left(\sigma_{j}-\sigma_{i}\right) p_{j} E_{p_{j} p_{i}} d \tau_{i} .
$$

The following proposition which is derived from equation (9), states sufficient conditions for welfare improving consumption tax reforms.

Proposition 1: Assume the existence of consumption and production generated pollution. Suppose that the $i^{\text {th }}$ good carries the lowest (highest) rate of excess taxation of consumption-pollution relative to all other goods i.e., $\left(\sigma_{j}-\sigma_{i}\right)>0(<0), \quad \forall j \in K$. Then, a small increase (decrease) of the consumption tax on this good, improves social welfare if the $i^{\text {th }}$ good is a substitute in consumption with all the other goods.

Note that the results of the above proposition do not depend on whether the rate of excess taxation is positive or negative. The reforms described by the above proposition aim at small increases or decreases of consumption tax rates so that the rates of excess taxation of consumption-pollution move towards uniformity. For example, in the case of the $i^{\text {th }}$ good carrying the lowest rate of excess taxation of consumption-pollution relative to all other goods we propose successive small increases of the consumption tax on this good, so that its rate of excess taxation of 
consumption-pollution does not increase beyond the level of the second lowest rate of excess taxation. Intuitively, the above results can be interpreted as follows. Take the case whereby the $i^{\text {th }}$ good exhibits the lowest rate of excess taxation of consumptionpollution, thus it is the good associated with the least distorted consumption-pollution. Then, increasing the consumption tax on this good so that its rate of excess taxation of consumption-pollution does not increase beyond the level of the second lowest rate, aims at bringing the consumption generated pollution distortions towards uniformity. This result depends on the relationship in consumption between the good with the lowest rate of excess taxation of consumption-pollution, and the other goods. Thus, assuming substitutability in consumption between the $i^{\text {th }}$ good and the other goods, an increase in the consumption tax on the $i^{t h}$ good reduces its consumption and pollution distortion and raises the consumption and pollution distortion generated by all other goods. An analogous argument holds when the $i^{\text {th }}$ good exhibits the highest rate of excess taxation of consumption-pollution, and the consumption tax on this good is reduced in such a way that, its rate of excess taxation of consumption-pollution does not fall below the level the second highest rate.

Comparing the above results to standard results of the literature on reforms of tariffs and consumption taxes we note the following. Michael et al. (1993) conclude that if, for example, the $i^{\text {th }}$ good is burdened with the highest (lowest) consumption tax rate, then, reducing (increasing) this tax rate to the level of the next highest (lowest) consumption tax rate, unambiguously improves the country's welfare if the $i^{\text {th }}$ good is a substitute to all other goods in consumption (Proposition 1, p. 421). This result seizes to hold when introducing consumption generated pollution. As shown above, a welfare improving reform of consumption taxes requires increasing (decreasing) the consumption tax on the commodity exhibiting the lowest (highest) rate of excess taxation of consumption-pollution, without inferring that this commodity is the one that is also burdened with the lowest (highest) consumption tax rate. In the presence, however, of only production generated pollution, then the welfare effects of a consumption tax reform go through as originally stated by Michael et al. (1993) and others. 


\subsection{Reforms in production taxes}

We now derive the conditions under which welfare improves by increasing or decreasing the production tax on a certain good. In this exercise we do not consider changes in consumption taxes whose non-zero levels are held constant. Whether there exist consumption generated pollution and/or consumption taxes does not affect the results to follow. ${ }^{16}$ Since consumption taxes do not change, equation (7) reduces to:

$$
\Omega d u=-\sum_{j=1}^{K}\left(t_{j}-\alpha_{j} E_{z_{j}}\right) R_{q_{j} q_{n}} d t_{n}=-\sum_{j \neq n}^{K}\left(s_{j}-s_{n}\right) q_{j} R_{q_{j} q_{n}} d t_{n} .
$$

Using equation (10), in the following proposition we state the sufficient conditions for welfare improving production tax reforms.

Proposition 2: Assume the existence of consumption and production generated pollution. Suppose that the $n^{\text {th }}$ good carries the lowest (highest) rate of excess taxation of production-pollution relative to all other goods i.e., $\left(s_{j}-s_{n}\right)>0(<0)$, $\forall_{j} \in K$. Then, a small increase (decrease) of the production tax on this good improves social welfare if the $n^{\text {th }}$ good is a substitute in production with all other goods.

Note that the results of the above proposition do not depend on whether the rate of excess taxation is positive or negative. The welfare improving reforms described by the above proposition aim at small increases or decreases of production tax rates so that the rates of excess taxation of production-pollution move towards uniformity. The intuition of these results follows the previous discussion of small reforms in the consumption tax rates. ${ }^{17}{ }^{18}$

\footnotetext{
${ }^{16}$ The size of $\Omega$ is different if consumption taxes are zero compared to the case where are not. The results of proposition 2, however, are the same in both cases, i.e., zero or positive consumption taxes.

${ }^{17}$ When the pollution from the consumption or production of different goods is homogenous and pollution intensities are also the same, then the rate of excess taxation of consumption or production pollution is the highest (i.e., $\sigma_{i}$ or $s_{i}$ is the highest) if and only if the tax rate is the highest (i.e., $\tau_{i}$ or $t_{i}$ is the highest).

${ }^{18} \mathrm{We}$ can design uniform changes in all consumption or production taxes that improve welfare. For example, if we change all consumption taxes by the same proportion $(0<\lambda<1)$ of the excess taxation of consumption-pollution, that is, $d \tau_{i}=-\lambda\left(\tau_{i}-\beta_{i} E_{r_{i}}\right)$, and $d \tau_{i}>(<) 0$ according to weather $\left(\tau_{i}-\beta_{i} E_{r_{i}}\right)<(>) 0$, then a uniform increase (decrease) in consumption taxes proportional to the negative (positive) excess taxation of consumption pollution improves welfare.
} 


\section{Reforms under a binding revenue constraint}

In this section we consider reforms in consumption and production taxes under the additional restriction that government revenue cannot change because of the reforms. Thus, contrary to the previous section, we can no longer consider a change in a single consumption or production tax but we need to consider changes in at least two of these taxes in order to keep government revenue unchanged. Accordingly, we consider the following three reforms: (i) changing one production tax and one consumption tax, (ii) changing two production taxes, and (iii) changing two consumption taxes.

\subsection{Reforms in consumption and production taxes}

Equations (7) and (8) are now used to examine the welfare implications of the aforementioned reform programs, as well as the required adjustments in tax rates in order to maintain government revenue constant. To facilitate the analysis, we rewrite equations (7) and (8) as follows:

$$
\begin{aligned}
& \Omega d u=p_{i}^{-1} F_{i} d \tau_{i}-q_{n}^{-1} B_{n} d t_{n}, \\
& \delta d u+p_{i}^{-1} G_{i} d \tau_{i}+q_{n}^{-1} D_{n} d t_{n}=0,
\end{aligned}
$$

where,

$$
\begin{aligned}
& F_{i}=p_{i} \sum_{j \neq i}^{K} p_{j}\left(\sigma_{j}-\sigma_{i}\right) E_{p_{j} p i}, G_{i}=\left[p_{i} E_{p_{i}}+\sum_{j \neq i}^{K} \tau_{j}-\tau_{i} E_{p_{j} p i}\right], \\
& B_{n}=q_{n} \sum_{j \neq n}^{K}\left(s_{j}-s_{n}\right) q_{j} R_{q_{j} q_{n}}, D_{n}=\left[q_{n} R_{q_{n}}+\sum_{j \neq n}^{K} t_{n}-t_{j} R_{q_{j} q_{n}}\right] .
\end{aligned}
$$

We rewrite equations (11) and (12) in the following matrix format:

$$
\left[\begin{array}{cc}
\Omega & -p_{i}^{-1} F_{i} \\
\delta & p_{i}^{-1} G_{i}
\end{array}\right]\left[\begin{array}{l}
d u \\
d^{\tau} \tau_{i}
\end{array}\right]=\left[\begin{array}{c}
-q_{n}^{-1} B_{n} \\
-q_{n}^{-1} D_{n}
\end{array}\right] d t_{n} .
$$

Solving the above equation, we obtain: 


$$
\begin{aligned}
& \Delta_{1}\left(\frac{d u}{d t_{n}}\right)=-p_{i} q_{n}{ }^{-1}\left(B_{n} G_{i}+F_{i} D_{n}\right) . \\
& \Delta_{1}\left(\frac{d \tau_{i}}{d t_{n}}\right)=-q_{n}^{-1}\left(\Omega D_{n}-\delta_{B_{n}}\right) .
\end{aligned}
$$

We assume that both tax rates are revenue increasing, i.e., the tax rates are on the "right" side of the Laffer curve. This assumption implies that $\Delta_{1}=p_{i}^{-1}\left(\Omega_{G_{i}}+\delta_{F_{i}}\right)$, the determinant of the left-hand-side coefficients matrix in (13), is positive. ${ }^{19}$ This is a standard assumption used extensively in the tax reform literature, e.g., see among others, Emran and Stiglitz (2005). The following proposition summarizes the conditions ensuring a welfare improvement due to an increase in the production tax $t_{n}$, adjusting appropriately the consumption $\operatorname{tax}^{\tau}{ }_{i}$, so that government revenue is held constant.

Proposition 3: Assume the existence of production and consumption generated pollution and that

(i) the $n^{\text {th }}$ good exhibits the lowest rate of excess taxation of productionpollution, i.e., $\left(s_{j}-s_{n}\right)>0, \forall_{j} \in K$, carries the lowest production tax, i.e., $t_{n}<t_{j} \forall j \in K$, and it is a substitute in production with all other goods,

(ii) the $i^{\text {th }}$ commodity exhibits the highest rate of excess taxation of consumption-pollution, i.e., $\left(\sigma_{j}-\sigma_{i}\right)<0, \forall_{j} \in K$, and it is a substitute in consumption with all other goods,

\footnotetext{
${ }^{19}$ Using equation (1) and (7), we write equation (12) as $-d T+\delta d u+p_{i}^{-1} G_{i} d \tau_{i}+q_{n}^{-1} D_{n} d t_{n}=0$. Treating $d u$ and $d T$ as endogenous in the previous equation and equation (11), and $d^{\tau}{ }_{i}$ and $d t_{n}$ as exogenous, it is shown that $\left(d T / d_{i}^{\tau}\right)=\Omega^{-1} p_{i}^{-1}\left(\Omega_{G_{i}}+\delta_{F_{i}}\right)=\Omega^{-1} \Delta_{1}$ and that $\left(d T / d t_{n}\right)=\left(q_{n} \Omega^{-1}\left(\Omega_{D_{n}}-\delta_{B_{n}}\right)\right.$. Since it is assumed that $\left(d T / d_{i} \tau_{i}\right)>0$, and $\left(d T / d t_{n}\right)>0$, then $\left(\Omega_{G_{i}}+\delta_{F_{i}}\right)$ and $\left(\Omega_{D_{n}}-\delta_{B_{n}}\right)$ must be positive.
} 
Then, a small increase in the production tax on the $n^{\text {th }}$ good, while reducing the consumption tax on the $i^{\text {th }}$ good to keep government revenue constant, increases social welfare. ${ }^{20}$

First of all note that condition $(i)$ of Proposition 3 ensures that $B_{n}$ is negative and $D_{n}$ is positive, and condition (ii) ensures that $F_{i}$ is negative. Since the determinant $\Delta_{1}$ is assumed positive, then from the above it follows necessarily that $G_{i}>0$. These imply (i) that in order to keep government revenue unchanged, any two taxes need to move in the opposite direction, i.e., for example, $\left(d^{\tau_{i}} / d t_{n}\right)<0$ in equation (15), and (ii) from (14) that an increase in $t_{n}$ and an associated decrease in $t_{i}$ raises welfare.

Finally, by the same procedure, one can easily examine the welfare implications of consumption tax reforms (i.e., changes in $\tau_{i}$ ) while appropriately adjusting the production tax $t_{n}$ so as to maintain constant government tax revenue. For example, from equations (13) and under the conditions in proposition 4, we can obtain:

$$
\left(\frac{d u}{d^{\tau}{ }_{i}}\right)=-\Delta_{2} p_{i} q_{n}{ }^{-1}\left(B_{n} G_{i}+F_{i} D_{n}\right)<0,
$$

where $\Delta_{2}=q_{n}^{-1}\left(\Omega_{D_{n}}-\delta_{B_{n}}\right)$ is positive. Equations (16) indicate that under the assumptions of the model and conditions similar to ones previously described, a small reduction of the consumption tax $\tau_{i}$, so as the highest rate of excess taxation of consumption-pollution of this good does not fall below of the second highest rate, and an appropriate increase in the lowest production tax rate $t_{n}$ improves the country's welfare and maintain constant the government revenue.

Next, under the constraint of constant government revenue, we identify the conditions for welfare improvement when the reform involves (i) only production taxes, and (ii) only consumption taxes.

\footnotetext{
${ }^{20}$ The aforementioned small increase in the production tax on the $n^{\text {th }}$ good is such that $t_{n}$ does not exceed the second lowest production tax rate and the rate of excess taxation of production-pollution does not increase beyond the second lowest rate.
} 


\subsection{Reforms in production taxes}

In this section, we consider changes in two production taxes, viz., for the $n^{\text {th }}$ and the $i^{\text {th }}$ good. In this case, we obtain:

$$
\begin{aligned}
& \Delta_{3}\left(\frac{d t_{i}}{d t_{n}}\right)=-q_{n}^{-1} \Omega D_{n}-\delta_{B_{n}}, \text { and } \\
& \Delta_{3}\left(\frac{d u}{d t_{n}}\right)=\left(q_{i} q_{n}\right)^{-1} B_{i} D_{n}-B_{n} D_{i},
\end{aligned}
$$

where $\Delta_{3}=q_{i}^{-1} \Omega_{D_{i}}-\delta_{B_{i}}$ is positive since both production tax rates are assumed to be revenue increasing. Appendix (A.1) provides the relevant algebra in deriving the above equations.

The right-hand-side term of equation (17), i.e., $-q_{n}^{-1} \Omega_{D_{n}}-\delta_{B_{n}}$, is negative since $t_{n}$ is revenue increasing tax. ${ }^{21}$ In equation (18), the expressions $B_{i}$ and $D_{i}$ for the $i^{\text {th }}$ good are similar to those for the $n^{\text {th }}$ good. The following proposition states the sufficient conditions for a welfare improving increase in $t_{n}$, when $t_{i}$ is reduced so that tax revenue remains constant.

Proposition 4: Assume the existence of production generated pollution and that

(i) the $n^{\text {th }}$ good is a substitute in production to all other goods, it exhibits the lowest rate of excess taxation of production-pollution, i.e., $\left(s_{j}-s_{n}\right)>0, \forall j \in K$, and it has the lowest production tax, i.e., $t_{n}<t_{j} \forall j \in K$.

(ii) the $i^{\text {th }}$ good exhibits the highest rate of excess taxation of productionpollution, i.e., $\left(s_{j}-s_{i}\right)<0, \forall j \in K$, and it is a substitute in production to all other goods.

\footnotetext{
${ }^{21}$ With changes only in production taxes alone, it can be shown that $\left(d T / d t_{n}\right)=q_{n}{ }^{-1} \Omega_{D_{n}}-\delta_{B_{n}}$.
} 
Then, a small increase in the production tax on the $n^{\text {th }}$ good and reducing the production tax on the $i^{\text {th }}$ good to keep government revenue constant, increases social welfare.

For the small increase in the production tax $t_{n}$ to raise welfare the right-handside term of equation (18) must be positive. ${ }^{22}$ Condition $(i)$ of Proposition 4 ensures that $B_{n}$ is negative and $D_{n}$ is positive, and condition (ii) ensures that $B_{i}$ is positive. Since the determinant $\Delta_{3}$ and $\delta$ is positive and $B_{i}>0$, then $D_{i}$ is positive. Therefore, $d u / d t_{n}>0$. The above proposition indicates that by moving the rates of excess taxation of production-pollution towards uniformity via reforms in production taxes, under certain conditions, increases welfare.

\subsection{Reforms in consumption taxes}

Finally, we consider changes in two consumption taxes and the relevant two equations can be obtained as follows:

$$
\begin{aligned}
& \Delta_{1}\left(\frac{d_{i}^{\tau_{i}}}{d \tau_{n}}\right)=-p_{n}^{-1}\left(\Omega_{n}+\delta F_{n}\right), \\
& \Delta_{1}\left(\frac{d u}{d \tau_{n}}\right)=p_{i} p_{n}^{-1}\left(F_{n} G_{i}-F_{i} G_{n}\right) .
\end{aligned}
$$

Appendix (A.2) provides the relevant algebra in deriving the above equations.

Equation (19) indicates that since both tax rates are assumed revenue increasing, when the consumption tax rate $\tau_{n}$ increases, the consumption tax $\tau_{i}$, must decrease to keep revenue constant i.e., $\left(d \tau_{i} / d^{\tau}{ }_{n}\right)<0 .{ }^{23}$ Using equation (20), the following proposition summarizes the sufficient conditions for a welfare improving reforms.

Proposition 5: Assume the existence of consumption generated pollution and let:

\footnotetext{
${ }^{22}$ The notion of a small increase in $t_{n}$ is similar to that noted in footnote 20 .

${ }^{23}$ Following footnote $(21)$, it can be shown that $\left(d T / d \tau_{n}\right)=\left(\Omega_{G_{n}}+\delta_{F_{n}}\right)$, which is assumed positive.
} 
(i) the $n^{\text {th }}$ good exhibit the lowest rate of excess taxation of consumptionpollution, i.e., $\left(\sigma_{j}-\sigma_{n}\right)>0,{ }_{j} \in K$, has the lowest consumption tax, i.e., $\tau_{n}<\tau_{j}, \forall_{j} \in K$, and be a substitute in consumption to all other good,

(ii) the $i^{\text {th }}$ good exhibit the highest rate of excess taxation of consumptionpollution, i.e., $\left(\sigma_{j}-\sigma_{i}\right)<0, \forall j \in K$, and be a substitute in consumption to all other goods.

Then a small increase in the consumption tax on the $n^{\text {th }}$ while decreasing the consumption tax rate on the $i^{\text {th }}$ good so as to keep government revenue constant, improves $_{\text {welfare. }}{ }^{24}$

For the increase in the consumption tax $\tau_{n}$ to raise welfare the right-hand-side term of equation (20) must be positive. Condition (i) of Proposition 5 ensures that $F_{n}$ and $G_{n}$ is positive, while condition (ii) ensures that $F_{i}$ is negative. Since, $\delta$ and $\Omega$ are positive, $\Delta\left(=p_{i}^{-1}\left(\Omega G_{i}+\delta_{F_{i}}\right)\right)$ is positive and $F_{i}$ is negative, then $G_{i}$ must be positive. Therefore, $\left(d u / d_{n}\right)>0$. The above proposition states that by moving the rates of excess taxation of consumption-pollution towards uniformity via reforms in consumption taxes, under certain conditions, increases welfare.

\section{Concluding Remarks}

Recent developments in the theory and practice of economic policy making acknowledge the adverse consequences of expanded economic activity on the quality of environment. Such environmental degradation must then be accounted for when evaluating the welfare and other economic effects of various economic policies. With this in mind, we note that the literature on tax reforms within an integrated system of indirect taxes (e.g., VATs, or other domestic or trade taxes) offers, thus far, a very limited insight on the welfare and government revenue implications of such tax reforms in the presence of pollution ridden economies. Thus, in this paper we revisit the question of reforming the structure of indirect taxes in the presence of production

\footnotetext{
${ }^{24}$ The aforementioned small increase in the consumption tax on the $n^{\text {th }}$ good is such that $\tau_{n}$ does not exceed the second lowest consumption tax rate, and the rate of excess taxation of consumptionpollution does not increase above the second lowest rate.
} 
and consumption-generated pollution, and we identify sufficient conditions under which such tax reforms improve welfare with and without a binding government revenue constraint.

The sufficient conditions under which the various tax reforms improve welfare with or without constant government revenue are stated in the relevant Propositions of the paper. Here, instead of restating these conditions, we note some analytical features related to our results. First, the presence of production generated pollution does not alter the known results of consumption tax reforms alone. Second, regardless of a binding revenue constraint, the proposed welfare improving reforms of production taxes alone, or of consumption and production taxes combined, are those bringing towards uniformity the rates of excess taxation of pollution. The same feature holds for the case of consumption generated pollution and of reforming consumption taxes so as to bring the rates of excess taxation of pollution towards uniformity. For example, consider the case of reforming production taxes alone. When there is no binding revenue constraint, a welfare improving reform entails increasing the production tax on the good exhibiting the lowest rate of excess taxation of pollution in a way such that this rate does not increase beyond the second lowest rate of excess taxation of pollution. When there is a binding revenue constraint, such a reform is accompanied by appropriate changes in the production tax on another commodity so that government revenue is kept constant. Third, regardless of the source of pollution, two of the critical conditions supporting the results are: $(i)$ the relationship in consumption and/or production between the good whose tax is changed to all other commodities, and (ii) under a binding revenue constraint, all reformed taxes are revenue increasing.

\section{APPENDIX}

\section{A.I Reforms in production taxes under pollution and a binding revenue constraint}

With changes only in production taxes $t_{n}$ and $t_{i}$, equations (7) and (8) respectively, become:

$$
\Omega d u=-\sum_{j \neq i}\left(s_{j}-s_{i}\right) q_{j} R_{q_{j} q_{i}} d t_{i}-\sum_{j \neq n}\left(s_{j}-s_{n}\right) q_{j} R_{q_{j} q_{n}} d t_{n},
$$




$$
\delta_{d u}+\left\lceil q_{i} R_{q_{i}}+\sum_{j \neq i} t_{i}-t_{j} R_{q_{j} q_{i}}\right\rfloor \frac{d t_{i}}{1-t_{i}}+\left[q_{n} R_{q_{n}}+\sum_{j \neq n} t_{n}-t_{j} R_{q_{j} q_{n}}\right\rfloor \frac{d t_{n}}{1-t_{n}}=0 .
$$

Equations (A.1) can be written in the following matrix system:

$$
\left[\begin{array}{cc}
\Omega & q_{i}^{-1} B_{i} \\
\delta & q_{i}^{-1} D_{i}
\end{array}\right]\left[\begin{array}{l}
d u \\
d t_{i}
\end{array}\right]=\left[\begin{array}{c}
-q_{n}^{-1} B_{n} \\
-q_{n}^{-1} D_{n}
\end{array}\right] d t_{n},
$$

where the definitions for $B_{i}, B_{n}, D_{i}$ and $D_{n}$ follow those given in equations (11) and (12). Equations (A.2) are then used to derive equations (17) and (18) in the text.

\section{A.II Reforms in consumption taxes under pollution and a binding revenue constraint}

With changes only in consumption taxes $\tau_{n}$ and $\tau_{i}$, equations (7) and (8) respectively, become:

$$
\begin{gathered}
\Omega d u=\sum_{j \neq i}^{K}\left(\sigma_{j}-\sigma_{i}\right) p_{j} E_{p_{j} p_{i}} d \tau_{i}+\sum_{j \neq n}^{K}\left(\sigma_{j}-\sigma_{n}\right) p_{j} E_{p_{j} p_{n}} d \tau_{n}, \\
\delta_{d u}+\left[p_{i} E_{p_{i}}+\sum_{j \neq i} \tau_{j}-\tau_{i} E_{p_{j} p_{i}}\right] \frac{d \tau_{i}^{\tau}}{1+\tau_{i}}+\left[p_{n} E_{p_{n}}+\sum_{j \neq n} \tau_{j}-\tau_{n} E_{p_{j} p_{n}}\right] \frac{d_{n}^{\tau}}{1+\tau_{n}} .
\end{gathered}
$$

Equations (A.3) can be written in the following matrix system:

$$
\left[\begin{array}{cc}
\Omega & -p_{i}^{-1} F_{i} \\
\delta & p_{i}^{-1} G_{i}
\end{array}\right]\left[\begin{array}{l}
d u \\
d \tau
\end{array}\right]=\left[\begin{array}{c}
p_{n}^{-1} F_{n} \\
-p_{n}^{-1} G_{n}
\end{array}\right] d_{n} \tau_{n}
$$

where the definitions for $F_{i}, F_{n}, G_{i}$ and $G_{n}$ follow those given in equations (11) and (12). Equations (A.4) are then used to derive equations (19) and (20) in the text. 


\section{References}

Abe, K., 1995, The target rates of tariffs and tax reforms, International Economic Review 36, 875-885.

Anderson, J., 1999, Trade policy reform with a government budget constraint, in Piggot, J. and A. Woodland (eds): International Trade Policy and the Pacific Rim, London: Mcmillan.

Atkinson, A.B. and Stiglitz, J.E., 1976. The design of tax structure: Direct versus indirect taxation, Journal of Public Economics, 6, 55- 75.

Beghin, J., D. Holst and D. van der Mensbrugghe, 1997, Trade and pollution linkages: piecemeal reform and optimal intervention, Canadian Journal of Economics $30,442-455$.

Beghin, J. and S. Dessus, 1999, Double dividend with trade distortions: Analytical results and evidence from Chile, American Journal of Agricultural Economics 81, 1999, 1305-1306.

Boadway, R. and M. Sato, 2009, Optimal tax design and enforcement with an informal sector, American Economic Journal: Economic Policy 1, 1-27.

Bovenbeg, L., 1999, Green tax reform and the double dividend: An updated readers guide, International Tax and Public Finance 6, 421-442.

Bovenbeg, L. and R.A. Mooij, 1994, Environmental levies and distortionary taxation, American Economic Review 84, 1085-1089.

Bovenbeg, L. and R. van der Ploeg, 1994, Green policies and public finance in a small open economy, The Scandinavian Journal of Economics 96, 3, 343-363.

Copeland, B., 1994, International trade and the environment: policy reform in a polluted small open economy, Journal of Environmental Economics and Management 26, 44-65.

Copeland, B. and S. Taylor, 1995, Trade and the environment: A partial analysis, American Journal of Agricultural Economics 77, 765-771.

Copeland, B. and S. Taylor, 2004, Trade, growth, and the environment, Journal of Economic Literature XLII, 7-71.

Diewert, W., A. Turunen-Red and A. Woodland, 1989, Productivity- and paretoimproving changes in taxes and tariffs, Review of Economic Studies 56, 199216.

Emran, S., 2005, Revenue-increasing and welfare-enhancing reforms on taxes on exports, Journal of Development Economics 77, 277-292. 
Emran, S. and J. Stiglitz, 2005, On selective indirect tax reform in developing countries, Journal of Public Economics 89, 599-623.

European Union, 2010, Green Paper on the future of VAT: Towards a simpler, more robust and efficient VAT system, European Commission, Brussels, December 2010.

Goulder, L., 1995, Environmental taxation and the double dividend: A reader's guide, International Tax and Public Finance 2, 157-183.

Fullerton, D., A. Leicester, and S. Smith, 2008, Environmental taxes, NBER Working Papers 14197, National Bureau of Economic Research, Inc.

Hatta, T., 1977, A theory of piecemeal policy recommendation, Review of Economic Studies 44, 1-21.

Hatta, T., 1986, Welfare effects of changing commodity tax rates towards uniformity, Journal of Public Economics 29, 99-112.

Hatzipanayotou, P., M. Michael and S. Miller, 1994, Win-win indirect tax reform: a modest proposal, Economics Letters 44, 147-151.

Hatzipanayotou, P., S. Lahiri, and M. Michael, 2005, Reforms of environmental policies in the presence of cross-border pollution and public-private clean-up, Scandinavian Journal of Economics 107, 315-333.

Kaplow, L., 2006, On the undesirability of commodity taxation even when income taxation is not optimal, Journal of Public Economics, 90, 1235-1250.

Kayalica, O. and O. Kayalica, 2005, Transboundary pollution from consumption in a reciprocal dumping model, Global Economy Review 5, Article 7.

Keen, M., 1987, Welfare effects of commodity tax harmonisation, Journal of Public Economics, 33, 107-114.

Keen, M. and S. Lahiri, 1998, The comparison between destination and origin principles under imperfect competition, Journal of International Economics, $45,323-350$.

Keen, M. and J. Ligthart, 2002, Coordinating tariff reduction and domestic tax reform, Journal of International Economics 56, 489-507.

Keen, M. and J. Ligthart, 2005, Coordinating tariff reduction and domestic tax reform under imperfect competition, Review of International Economics 13, 385-390.

Lahiri, S. and A. Nasim, 2005, Commercial Policy Reform in Pakistan: Opening up the Economy under Revenue Constraint, International Tax and Public Finance 12, 7234-739. 
Lockwood, B., D. Meza, and G. Myles, 1994, When are origin and destination regimes equivalent? International Tax and Public Finance, 1, 5-24.

Michael, M., P. Hatzipanayotou and S. Miller, 1993, Integrated reforms of tariffs and consumption taxes, Journal of Public Economics 52, 417-428.

Mujumdar, S., 2004, Revenue implications of trade liberalization under imperfect competition, Economics Letters 82, 83-89.

Naito, T., 2005, Revenue-neutral environmental tariff reform, growth and welfare, Review of International Economics 13, 985-996.

Naito, T., 2006, Growth, revenue, and welfare effects of tariff and tax reform: Winwin-win strategies, Journal of Public Economics 90, 1263-1280.

Naito, T. and K. Abe, 2008, Welfare- and revenue-enhancing tariff and tax reform under imperfect competition, Journal of Public Economic Theory 10, 10851094.

Neary, J., P., 1998, Pitfalls in the theory of international trade policy: Concertina reform of tariffs and subsidies to high technology industries, Scandinavian Journal of Economics 100, 187-206.

Saez, E., 2002, The desirability of commodity taxation under non-linear income taxation and heterogeneous tastes, Journal of Public Economics, 83, 217 230 .

Turunen-Red, A. and A. Woodland, 2004, Multilateral reforms on trade and environmental policy, Review of International Economics 12, 321-336.

Wilson D. J., 1991, Optimal public good provision with limited lump-sum taxation, American Economic Review 81, 153-166.

World Bank, 2002, World development Indicators 2002, World Bank, Washington, DC. 